\title{
Efficiency of vermicompost production and use in agriculture
}

\author{
Elena Shetinina ${ }^{1}$, Arina Shetinina $^{1}$ and Irina Potashova ${ }^{1, *}$ \\ ${ }^{1}$ Sochi State University, Sochi, Sovetskaya st., 26a, 354000, Russia
}

\begin{abstract}
The relevance of the study is due to the need to eliminate the environmental problems associated with the irrational use of chemical fertilizers in agriculture. Biohumus is an environmentally friendly natural fertilizer, which is produced by processing food waste ringworms, whose natural habitat is compost mass and not mineral soils. Thus, the production does not violate the flora and fauna and at the same time is environmentally friendly and waste-free. Practical significance of the study consists in the development of measures, the implementation of which will allow solving environmental problems caused by the irrational use of chemical fertilizers. As part of the study, the authors proposed using biohumus as a natural fertilizer, which allows, on the one hand, reducing the chemical effect on the soil cover, reducing the chemical elements content in finished agricultural products, eliminating the plants treatment with pesticides, and on the other hand, increasing the natural yield, developing immunity in plants of various species, and improving the physical properties of the soil layers.
\end{abstract}

\section{Introduction}

An alternative to chemical fertilizers is biohumus, which is a complex microbiological fertilizer, a product of the organic agricultural processing waste by earthworms.

The purpose of the study is to develop recommendations and find alternative ways to solve environmental problems associated with the use of chemical fertilizers.

In accordance with the purpose of the study objectives:

- describe the main categories of the categorical conceptual apparatus, such as ecotope, biogeocenosis, trophic chain, manure worm, soil metabolism, vermicomposting, vermicultivation, and others;

- study the theoretical aspects of this problem;

- substantiate the benefits of using biohumus for fertilizing soils in agriculture;

- calculate the economic indicators of the biohumus production efficiency;

- justify the cost-effectiveness of proposals related to the elimination of land use environmental problems.

\footnotetext{
* Corresponding author: potashova@mail.ru
} 
An analysis of the literature has led to the conclusion that there are contradictions in the assumptions of scientists and their contradictory statistical data regarding some environmental issues related to fertilizer application to the soil.

On the one hand, it is believed that in the Russian Federation, the Law "On Consumer Protection" is observed, and the finished plant products comply with all environmental and sanitary-epidemiological indicators. On the other hand, the audit data of the Accounts Chamber show that due to the chemical fertilizers use, most of the land in our country is not usable. The next problem is that despite the attempts of Thomas J. Beretta (the founder of vermicultivation), there are only technologies for small-scale production of organic fertilizer - biohumus. On an industrial agricultural scale, this product is not used, as there is no technology for large-scale production. Also, the problem lies in the practical finding of markets for these products. Since biohumus has never received widespread use of organic fertilizer. Some farmers do not have comprehensive information about this type of fertilizer. This study is aimed primarily at solving the tasks and developing directions in solving the stated problems in this area. At the present stage, the world economy and the state economy consists of the industry several segments. One of the economy segments in the modern market system conditions of economic relations is agriculture. For a more detailed consideration of the problems stated in the study should study the "agriculture" concept. Agriculture is a branch of the economy, a sphere of national economy, aimed at providing food to the population of the state. Agriculture provides the needs of most food and raw materials for the food industry [1].

The state's food supply depends on the state of this sector of the economy. Considering that a person is a biosocial being, it should be noted that satisfaction of both existential (social) needs and primary biological needs is required. Thus, the branch of agriculture, providing primary biological needs (such as the consumption of food and fluids for the body functioning), plays a key role in the economy, is one of the most important segments.

The branch of agriculture is a systemic phenomenon, since the branch of agriculture includes such fields of activity as agriculture, plant growing, cattle breeding, cattle breeding, etc. Legal regulation of this field of activity falls under the scope of legal regulation of constitutional law, environmental law, land law, and other special branches of the law of the Russian Federation legal system, as well as this area is governed by certain international treaties ratified by the Russian Federation in accordance with international law and national legislation. In some countries of the world, the agriculture system also includes such activities as hunting, fishing, and gathering food. In the doctrine of Russian law is a different trend. In Russian law, it is determined that agriculture is an activity aimed at the production of food and other raw materials. This assumption comes from the history of the emergence of agriculture, as a branch of the economy. Since agriculture appeared in the era of the "Neolithic revolution" in the means of production, which led to the emergence of a productive economy, with which historians associate the subsequent development of certain civilizations [2].

Thus, it is assumed that agriculture is a producing enterprise, and not appropriating on the basis of this, the specifics of the legal regulation of certain types of activities belonging to different branches of the agricultural sector are formed.

\section{Methods}

In the process of solving the tasks set, the methods were used. In the course of the study, such general scientific and special research methods as the system approach, comparative analysis, logical generalization, empirical observation were used.

The information and empirical basis of the research is presented by research materials of domestic and foreign scientists on the effective use of fertilizers, plant cultivation, the 
environmental situation in countries around the world, the use of worms in the agricultural sector, articles and periodicals, data and materials posted on the Internet.

\section{Results}

In the economic aspect, the Russian Federation considers the attribution of certain types of activities to the agricultural sector, thus, the complex of agriculture sub-sectors can be attributed to two large groups: animal husbandry and crop production (agriculture).

In this study, special attention is paid to crop production (agriculture). In the aspect of the agro-industrial complex of agricultural sub-sectors, plant growing is the cultivation of cultivated plants, one of the main sub-sectors of agriculture. The purpose of crop production is the crop products production, which provides the population with food, feed for livestock, raw materials of plant origin for textile, pharmaceutical, perfumery and other production [3].

The cultivation of cultivated plants is directly related to the processing of soil fertile layers of the earth. Fertile soil layer is a humified part of the soil cover, which possesses positive properties necessary for the plant. The complex of such properties includes chemical, physical, and biological properties of soil cover [4].

The properties of soil cover as indicators form a general ecological picture of the soil state. The Constitution of the Russian Federation regulates the legal framework for the use of land resources in the state. Clause 1, Article 9 of the Russian Federation Constitution reads: "Earth and other natural resources are used and protected in the Russian Federation as the basis of the life and peoples living activities in the relevant territory".

Thus, we can conclude that land is the value of the material world, which is protected in the Russian Federation through legal regulation of land use. Since the land is the heritage of the Russians and is protected by the rules of law, the environmental aspect of crop production should be considered. In the current environmental situation in the world should be considered environmental problems. An ecosystem is a complex self-regulating and selfdeveloping system. The main characteristic of an ecosystem is the presence of relatively closed material and energy flows between the biotic and abiotic components of the ecosystem that are stable in space and time [5].

The structure of an ecosystem is a combination of biotic and abiotic elements. Biotic elements are organisms that receive primary energy for existence from photo- and chemosynthesis or producers, as well as organisms that receive energy from the oxidation of organic substances. These organisms form the trophic (food) structure of the ecosystem [6]. The trophic (food) chain of an ecosystem is a relationship between organisms, in which the transfer of substances and energy occurs by eating one organism by another, higher class of organisms [7]. As a result of such ecological relationships, a chain transfer of the substance is carried out, which underlies the cycle of substances in nature.

The main elements of the ecosystem can be considered the climatic regime, which determines the physical indicators of the environment; organic compounds that are the link between the biotic and abiotic elements of the circulation of substances in nature; inorganic substances that are also present in the circulation of substances; producers, which are organisms that produce primary products of vital activity; microchanges (saprotrophs) fungi and bacteria that destroy the dead particles of organic matter; macrochanges (phagotrophs) are heterotrophs that feed on other organisms or large particles of organic matter. These elements ensure the functioning of the ecosystem, and the producers, microcans, macrocans are the ecosystem biomass.

In science, there is also a classification of organisms that make up the biological mass of biophages and saprophages. Biophages are organisms that feed on other living organisms. Saprophages are organisms that feed on dead particles of organic matter. This classification 
is carried out primarily on a functional basis. There is also a temporary basis for the classification, since, for example, if biophages feed on living organisms and this process does not take a long time, then saprophages process organic matter for a long time. It is possible to trace the functional-temporal relationship between these organisms. Since eating biophages of living organisms causes, including the processing of organic substances by saprophages. Since from the essence of economic processes and the essence of agriculture in the process of circulation of substances man enters. The human factor causes the problem of the ecological state of soil cover, as well as the state of the land resource as a whole. Agriculture, as producing human activity has a great impact on the environment. The cause of the ecological problem is a whole complex of human interventions in the ecosystem. In this study, the influence of man on land resources should be considered.

The hardest effect on the environment is the result of farming in agricultural activities. Impact is a combination of factors such as plowing land, tillage, land reclamation, as well as the use of mineral and chemical fertilizers. These factors lead to such environmental problems as the destruction of the soil ecosystem as a whole; loss of humus mass; compaction of soil layers, which leads to the impossibility of further expedient use of the land resource; destruction of soil structure; to various types of soil erosion, such as water or wind erosion. The use of mineral or chemical fertilizers has contributed to the emergence of another problem. At the end of the 20th century, as a result of declining crop productivity, it became necessary to use additional fertilizers to increase production efficiency, i.e. increase the fertility of agricultural land. These measures have led to the fact that at this stage of development of the industry there was a problem of the content of harmful substances in food (nitrates, pesticides, hormones).

The cause of all was the global dehydration of the soil layer due to the lack of consistency and expediency of using the natural earth resource, namely, uncontrolled crops of various crops, grazing of animals and mining, as well as the extermination of certain types of organisms. In 2005, the Accounts Chamber of the Russian Federation audited the effectiveness of environmental protection in the Russian Federation in 2005-2007, the result of this audit is the conclusion that approximately $1 / 6$ of the state total territory is environmentally unfriendly, which affects the level of agricultural production and quality of products. This problem is complex, as it affects both the economic and social sphere of society, and also affects the environmental safety of the state. One of the most pernicious factors affecting land resources is the use of various chemical or mineral fertilizers.

Chemical (mineral) fertilizers are inorganic chemical compounds that contain the nutrients needed to increase the productivity of plants. Nutrients, in turn, are various chemical compounds in the form of mineral salts. Conduct the following classification of chemical fertilizers into simple and complex. Simple mineral fertilizers contain one nutrient in their composition. Such fertilizers include phosphate, potash, nitrogen, etc. Complex mineral fertilizers contain two or more nutrients.

This type of fertilizer is relatively inexpensive, since the average price on the market for this product is 45 rubles per kilogram, but since it is a dry and free-flowing product, it requires certain technological measures for the transportation, processing and storage of this type of fertilizer, which contributes to new costs. The key is the technology of loading, transportation and storage as the overall environmental situation will depend on the method of loading, transportation and storage. Additional pollution of the atmosphere during reloading, transportation, and storage occurs due to the open method of technology of these measures required for the use of this product. Thus, chemical or mineral fertilizers harm not only the soil layers, but also the atmosphere. The release of chemical compounds leads to an increase in air temperature due to the release of energy, as well as to the emergence of so-called "chemical clouds", which subsequently cause precipitation with impurities of 
chemical elements and adversely affect the human body, property of citizens, the quality of drinking water, living organisms and the ecosystem as a whole.

The use of chemical fertilizers has a great impact on the soil, but the question of the benefits or harms of this effect is actively stirred up by lively discussions. For example, scientists of the USSR believed that the uncontrolled use of mineral fertilizers would lead to mutation of some plants. It was also believed that fruits grown using the technology of fertilizing soil with chemical compounds deteriorated faster as a result of chemical reactions of half-life, the process of decay accelerated, which was unacceptable in a tough planned economy. In the conditions of a modern market economy, this issue is only of secondary nature and is an indicator of the effectiveness of sales of agricultural products in the form of food and raw materials. However, the issue of the these products safety for the human body, as well as the environmental safety of this technology, is very acute. Since chemical intervention in the turnover of nutrients in an ecosystem can have a detrimental effect on the soil.

On the other hand, foreign scientists of the leading countries in terms of GDP indicators believe that the use of technology to fertilize soils with mineral fertilizers is the only possible solution in the face of a planet growing population and an unlimited growth in the needs of society. Scientists believe that the yield of cultivated plants directly depends on the amount of used mineral fertilizers. So, for example, the largest dosages of mineral fertilizers are used in France with yield indicators of 74 centners per hectare, in England with indicators of 70 centners per hectare and in Holland with indicators of 83 centners per hectare of land. This technology of using the overwhelming mass of mineral fertilizers to increase yields is due primarily to a shortage of land resources in the territory of these countries, which could be used for the cultivation of cultivated plants [8].

Considering this issue in a comprehensive way, it can be concluded that despite the influence of chemical fertilizers on agricultural efficiency indicators, of course, chemical fertilizers have an impact on the composition of the soil and the ecosystem as a whole and this effect is not always positive.

However, chemical fertilizers are not the only kind of fertilizer on the market. An alternative type of fertilizer is organic fertilizer - biohumus (vermicompost).

\section{Discussion}

Vermicompost (biohumus) is an organic fertilizer, a product of the processing of organic agricultural waste by earthworms. Thus, the formation of vermicompost is a natural ecological peaty process of turnover of soil nutrients.

In the production of vermicompost, earthworms of the species Eisenia foetida and Lumbricus rubellus, as well as other organisms contained in the earth soil layers, such as fungi, bacteria, insects and others, are most often used. A special role in this process is played by earthworms.

Eisenia foetida (dung-worm) is most often used in the process of vermicultivation, since according to its physiological characteristics it is best suited for the production of vermicompost. The dung worm is a representative of the small-cheeked worm species from the Lumricidae family. The length of the worm's body is from 6 to $10 \mathrm{~cm}$. The body has 105 segments, each of which has a distinctive purple ring. Body color has a reddish-brown color. Compared to other earthworms, the dung-worm is characterized by increased mobility, which is necessary for efficient technological production of vermicompost, and also the worms have well-developed protective functions, which facilitates the sampling of technological worms during production. In the process of vermicultivation, the manure worm allows to process various types of organic waste into the environmentally friendly fertilizer "vermicompost" or "biohumus". 
As an organic fertilizer vermicospost improves the structure, as well as water and physical properties of the soil. Increases the efficiency of soil cultivation, as in the process of vermicomposting weed seeds pass through the earthworm body and thus lose their germination, which saves resources on weeding of arable land. In addition, compared with other organic fertilizers, such as manure, the risk of infection with E. coli when using finished products is reduced, which dramatically increases the safety of the product.

The production technology founder of this fertilizer type is Thomas J. Berret. Berrett called the process of vermicompost formation vermiculturing. At his Earthmaster farms farm, which literally translates from English as a land master, Thomas J. Berrett created a whole ideological concept to convince gardeners, farmers and professional farmers in the value and potential importance of using this product in the agro-industrial complex.

However, vermicultivation is not limited only vermicompony. Vermicultivation is the process of growing a population of earthworms in artificially created conditions for this. The product of vermicultivation, that is, earthworms can be used for sale to other individual entrepreneurs or legal entities involved in vermicultivation; for sale to individuals and legal entities or individual entrepreneurs engaged in fishing; for receiving feed protein or biologically active substances.

Vermicomposting, in turn, is a directly technological process of processing organic materials into a humus-like mass. The product of this process is organic fertilizer biohumus or vemirocompost. The complex of the biohumus positive effect on the soil is a combination of elements, such as the rapid restoration of the soil natural fertility; rapid increase in the level of crop yields; ensuring plant immunity to various diseases; crop environmental sustainability.

The production of vermicompost or vermicompost is an uncomplicated technological process. The efficiency specificity and environmental friendliness of this production is caused by the ecotope of manure worms, i.e. natural habitat. The worms natural habitat is the land cover of the biogeocenosis, mainly the biomass of dead organic substances that are in the process of decay. Such organic masses are the fallen remnants of vegetation, the remains of the excreta of living creatures in fertile soils rich in particles of organic matter, such as tubers of cultivated plants, rhizomes, etc. In the process of decay in this environment, favorable conditions are created for the life of the worm population, as in the process of decay, additional energy is produced in the form of heat, as well as in the process of heat generation a condensation liquid is formed, which makes the soil warm and moist. Thus, it can be noted that the soil cover, which has a warm temperature and high humidity, acts as an ecotope of the manure worm. This specificity and determines the technological conditions for the production of vermicompost and vermicultivation in general. The conditions of the dung-worm ecotope are artificially created. For this purpose, it is necessary to create conditions for a closed system of manure management, since their mobility will significantly expand the habitat of the population created in artificial conditions. Thus, for keeping the manure worm, restrictive containers with a closed bottom and restrictive planes on the sides are necessary in order to avoid the loss of the worms and speed up the producing the finished product process from raw material organic waste.

Since the natural habitat of the worms is land cover, the cost of electricity for lighting premises during vermicultivation can be avoided, except for the costs of lighting the room during irrigation and sampling of worms.

The irrigation process is necessary to give the necessary consistency to the substrate (the primary organic processed mass) to move the worms and increase mobility.

In order to evaluate the efficiency of production, it is necessary to understand the reproduction process of the dung worm. Since it is believed that a population bred in artificial conditions on a vemiroferme can be considered viable only when there are 1,500 
individuals, calculations should be made taking into account the reproduction characteristics of these living organisms.

A population of 1,500 is considered to be royal. For further development, uterine stock should contain both mature adult individuals of Eisenia foetida and cocoons with not yet bred worms. Under natural conditions, from 1 to 21 eggs can be found in a cocoon, which is a multiple of 1 to 21 worms from one cocoon hatched from the cocoon.

Taking into account the peculiarities of breeding worms, we can conclude that, on average, there are 10 larvae per one mature worm. As a result, on the uterus in 1500 mature individuals, during the mating period of 2-3 weeks, there will be on average 15000 individuals of young stock, which will be 10 mother families in the warm period of time. Taking into account normal business risks, it is possible to calculate in five times the amount, i.e. for every 1500 adults 7500 mass of young animals. Young, i.e. the worms that have just hatched from the cocoon will reach sexual maturity in about 12 to 20 weeks and will be able to produce offspring, forming new uterine families.

The technological worms productivity in the vermicompost production process should be calculated taking into account the ratio of the individuals or uterine families number to a certain volume unit of the processed organic mass (number of individuals x m3 organic mass), also take into account the time unit during which the substrate is processed production amounts to weeks and months).

On average, the processing of $1 \mathrm{~m} 3$ of the substrate requires 600 adults during one month of the warm period (from March to October), but since the environment that is created artificially can be maintained throughout the year, the productivity period is also possible to increase or make it cyclical. Changeable cycles can be divided into 3 groups: the breeding phase, the production phase, the sampling phase of individuals. To control the amount of substrate is necessary to maintain the required number of individuals of the effective production phase.

Initially, the organization of the process of vermicultivation requires a land plot. For average production volumes 6 hectares of land will be enough. Taking into account the real estate market specifics in Sochi (Krasnodar Regoin, Russian Federation), a long-term lease agreement for a land plot should be concluded in this case; on average, the fulfillment of lease obligations will be payments of 60 thousand rubles per month. You can also take a consumer loan for the purchase of a plot. The average cost of land in the city of Sochi, the size of 6 acres, will be about 3 million rubles. If you make a loan calculation in Sberbank, then with a current lending rate of $12.9 \%$ and a loan period of 60 months (5 years), as well as the requested amount of 3 million, the monthly payment will be 68,642 rubles 70 kopecks. The total overpayment on the loan will be $37.92 \%$, which is equivalent to the sum of 1,118,562 rubles 59 kopecks. From the point of view of these expenses duration, you should choose a crediting option, since obligatory payments - expenses on crediting payments will be made for a period of 60 months, and mandatory payments of rent will be made throughout the entire process of the vermferme operation. The feasibility of this choice should be assessed, given the normal business risks.

Further, for the organization of production requires the substrate purchase. The substrate is an organic mass of particles of substances necessary for feeding the worms. This mass can be organic food waste, a lot of animal experiments of various kinds, hay, tree leaves and much more. Substrate harvesting is the most time consuming process, since the substrate must go through a stage of decay for some time and only after that it is possible to occupy technological worms. It is necessary to decompose the substrate mass with a layer of $50 \mathrm{~cm}$ in open space, in order to accelerate the process of decay, irrigate the whole mass with warm water and cover it with a film. The process of decay will take from 2 to 4 weeks. The substrate purchase and transportation will be another item of expenditure. The average 
substrate mass cost the is 5 rubles per $1 \mathrm{~kg}$. On average, $1 \mathrm{~m} 3$ contains $100 \mathrm{~kg}$ of substrate. Thus, 100 substrates will cost 500 rubles.

For the maintenance of the worms and fertilizer production, special conditions will be necessary, namely greenhouse-type rooms with an area of $10 \mathrm{~m} 2$ and 10 units with an average cost of 10,000 rubles each (the total purchase price is 100,000 rubles). Purchase of technological containers (creation of technological containers) will be 30,000 rubles. Purchase of irrigation hoses will be 2000 rubles. You should also consider the wages of 3 workers 60,000 rubles. Also, utility payments per month will amount to 4,000 rubles.

When the harvested substrate and conditions of the worms will be ready, it will be possible to proceed to the next preparatory stage - the purchase of worms. At the initial stage, the possible profit can be calculated by calculating the performance of technological worms with their average number. One mother family in 1500 individuals has a cost of 2500 rubles. Since in the period of 4 weeks for the processing of $1 \mathrm{~m} 3$ of the substrate, 600 individuals are necessary, it is necessary to calculate the average income per month in order to estimate the profitability.

With an average cost of $1 \mathrm{~kg}$ of vermicompost at 10 rubles, it can be calculated that when developing $1 \mathrm{~m} 3(100 \mathrm{~kg})$ of the substrate and the required number of worms per 600 individuals, $1 \mathrm{~m} 3$ of fertilizer will cost 1000 rubles. If you increase the amount of biomass from 600 to 1500 in $1 \mathrm{~m} 3$, you can reduce the production time from 4 to 1 week. Thus, from $4 \mathrm{~m} 3$ of the processed substrate 4,000 rubles can be obtained per month ( $400 \mathrm{~kg} \mathrm{x} 10$ rubles with 1500 individuals of worms). With an area of production greenhouse premises of $100 \mathrm{~m} 2$ and $10 \mathrm{~m} 2$ each, you can install 12 cultivator containers $(12 \mathrm{~m} 3)$ with a volume of 1 $\mathrm{m} 3$. Thus, it is possible to receive 48,000 rubles per month from one greenhouse room, and 480000 rubles from all greenhouse areas.

It should be noted that the enterprise profitability directly depends on the number of technological worms in the artificial population. It is necessary to calculate the worms number for production. With greenhouse areas of $100 \mathrm{~m} 2(10 \mathrm{~m} 2$ each 10 rooms $)$ and with a productivity of 1500 individuals $1 \mathrm{~m} 3$ / week, as well as placing 12 technology containers ( $1 \mathrm{~m} 3$ ), it should be noted that for 120 technology containers 120 mother families will be required $(120 \times 1500)$. With an average cost of a uterine family of 2500 rubles, the purchase of worms will cost 300,000 rubles. These calculations are made taking into account the full production.

Then, after purchasing the land (making use of the lease), preparing the substrate and creating the conditions of detention, after purchasing technological worms, you can proceed to start the production cycle. The production cycle is a process of vermicultivation. The cycle consists of 4 phases: the breeding phase of the worms, when mating and hatching of young stock from cocoons occurs. During this period, worms and cocoons are very vulnerable to physical impact. When sampling, it is very easy to damage both adults and cocoons. Despite the worms regenerative peculiarities, if the worm is removed up to 30 body segments, it can restore the lost body weight, but the blankets do not have such regenerative features. Specificity of reproduction causes this phase as a stage of inactivity for 2 weeks; the phases of processing organic agricultural waste with worms at the rate of 1500 individuals x $1 \mathrm{~m} 3$ / week; phase of sampling worms and sowing the finished product, technologically, this process can be represented as separating the worms from the mass of vermicompost, the whole compost mass is sifted through the boxes with the mesh bottom and the worms mass is traced through the box with the smaller mesh. Thus, additional enrichment with oxygen is provided. The next phase is the wintering phase of the worms, when the mobility of the worms decreases due to seasonal changes (December, January and mid-February).

During the whole production time, the phases will replace each other. An exception can be the breeding phase and the production phase, since during breeding the worms also 
process organic waste, but for 2 weeks of mating and hatching the worms from the cocoons cannot be extracted from the mass of vermicompost.

\section{Conclusions}

Finished products can be sold on the fertilizer market as vermicompost. The founder of vermicultivation, Thomas J. Berret, spoke about the quality and environmental friendliness of this fertilizer. The effectiveness of this fertilizer, he said, should be given in numbers. So at the presentations of the product, he talked about a potato harvest of 100 tons per hectare, about a harvest of onions 80 tons per hectare. He obtained these results when growing plants on vermicompost at the Earthmaster farms factory. Agrarian studies show that when using vermicompost, the crop is doubled, the vegetable product taste is improved, and the plant does not require additional external processing with pesticides.

The main competitor in the fertilizer market is chemical fertilizers that accumulate in consumer products and have a detrimental effect on the human body, directly or indirectly. Under the direct adverse effects should be understood as the consumption of food processed chemicals. Mediated exposure can be viewed as feeding these animal products intended for agricultural needs (cattle, small ruminants, birds, etc.). Chemical elements of fertilizers tend to accumulate in the human body and cause cancer, nervous system disorders, the development of allergies, the occurrence of problems with the gastrointestinal tract, as well as a decrease in brain activity and the deterioration of the body state as a whole. From the point of view of human health, it is more expedient to use organic fertilizer active biohumus. This production technology is less expensive than the production of chemical fertilizers. The process is biologically natural and does not harm biogeocenosis.

Thus, summing up the research, it can be said that biohumus is an effective organic fertilizer. The process of biohumus production is a natural process of the first organic waste treatment. Production and its specificity are caused by the creation of an ecotope of the worms range in an artificial environment. The profitability of this production is confirmed by calculations. The value of this type of fertilizer is primarily in its ecological qualities, as well as in the absence of influence on the human body.

\section{References}

1. B.A. Roizenberg, L.S. Lazovsky, E.B. Starodubtseva, Modern economics dictionary (INFRA-M, Moscow, 1999)

2. A. Davidson, T. Jaine, The Oxford companion to Food (Oxford University Press, Oxford, 2014)

3. A. P. Gorkin, Geography: Modern illustrative encyclopedia (Rosman, Moscow, 2006)

4. A. P. Gorkin, Geography: Modern illustrative encyclopedia (Rosman, Moscow, 2006)

5. N. I. Nikolaykin, N.E. Nikolaykina, O. P. Melikova, Ecology (Drofa, Moscow, 1999)

6. U. Odum, Fundamentals of Ecology (Mir, Moscow, 1975)

7. M. Begon, J. Harper, K. Taudsen, Ecology. Individuals, populations and communities (Mir, Moscow, 1989)

8. R. S. Acabarev, Regulation of agriculture. Positive aspects of foreign (Bulletin of the Irkutsk State University, Irkutsk, 2015) 